\title{
Factors Affecting Development of Rancid Off Odor in Cooked Fish Meats during Storage at $5^{\circ} \mathrm{C}$
}

\author{
Chiaki Koizumi,* Shun Wada,* and Toshiaki Ohshima* \\ (Accepted March 13, 1987)
}

\begin{abstract}
To investigate factors affecting development of rancid off odor or flavor in cooked fish meat during storage in a refrigerator at $5^{\circ} \mathrm{C}$, rates of lipid oxidation of the cooked meats of various species of fish were compared to each other by using TBA test and then infuences of water-extract of fish meat on the lipid oxidation were examined. Rates of increases in TBA values of cooked white muscles of fish examined here during storage were as follows; saury $>$ mackerel $>$ sardine $>$ horse mackerel $>$ flying fish $>$ sablefish $>$ halibut $>$ dusky sole. White meat species such as sablefish, halibut and dusky sole were essentially not susceptible to rancidity. The susceptibility of white muscle of mackerel to rancidity was reduced remarkably by repeated extractions with water prior to cooking. Further, the dialysed water-extract of mackerel meat showed much higher activity to cause rancidity of water-extracted mackerel meat than the diffused solution.

From these results, heme pigment present in the fish muscle was suspected to be a major catalyst responsible for the development of rancidity after cooking.
\end{abstract}

Sardine and mackerel meats develop off odor or flavor upon cooking, which gradually increases in intensity during storage for a relatively short period of time in a refrigerator. This off odor probleme gives rise to a difficulty in increase of human consumption of these species of fish. In the previous paper, ${ }^{1)}$ it was demonstrated that the development of off odor in fish meat upon cooking was related to the oxidation of lipids.

Zipser and Watts ${ }^{2}$ reported that flavor deterioration of cooked mullet meat during refrigerator storage resulted from the oxidation of both stored lipids and phospholipids. Recently, Younathan et al. ${ }^{3)}$ showed that development of off odor in the cooked mackerel meat could be reduced to some extent by addition of hot water-extract of yellow onion. However, limited informations have been available on the mechanism of oxidative reaction responsible for the development of rancidity in cooked fish meats.

On the other hand, rancidity resulting from lipid oxidation in beef, pork, chicken meat and turkey meat after cooking, refered to as warmedover flavor, ${ }^{4-\theta}$ ) have been studied extensively so far. As a result, it has been generally accepted that the lipid classes primarily involved in the oxidative reaction are phospholipids rather than triglycerides ${ }^{7-10)}$ and that nonheme iron, not heme pigment, is implicated as a major prooxidant of the lipid oxidation. ${ }^{11-17)}$

In this study, rates of lipid oxidation of the cooked meats of various species of fish which contained lipids and myoglobin at different concentrations were compared to each other and then influences of water-extract of fish meat on lipid oxidation were examined to investigate factors affecting development of rancid off odor or flavor.

\section{Materials and Methods}

\section{Fish Sample}

Dusky sole Lepidosetta mochigarei, halibut Hippoglossus stenolepis, sablefish Anopoploma fimbria, flying fish Prognichthys agoo, horse mackerel Trachurus japonicus, sardine Sardinops melanostictus, saury Coloabis saira and mackerel Scomber japonicus were used. They were purchased from a local fish store in either fresh or frozen states, except for halibut which was offered from Nichiro Fishery Co., Ltd.

\section{Cooking and Storage Conditions}

White and red muscles of fish were removed and minced separately. Ten $-30 \mathrm{~g}$ of the minced sample was placed in a petri dish and cooked in an autoclave at $100^{\circ} \mathrm{C}$ for $15-60 \mathrm{~min}$. After cooking, the sample was ground finely in a mortor, placed back to the petri dish and stored in a refrigerator

* Department of Food Science and Technology, Tokyo University of Fisheries, Konan, Minato, Tokyo 108, Japan (小泉千秋, 和田 俊, 大島敏明: 東京水産大学). 
at about $5^{\circ} \mathrm{C}$. Uncooked samples were used as controls.

\section{Evaluation for Rancidity}

Extent of rancidity developed in fish meat was evaluated with TBA test. For this purpose, the method of Sinnhuber and $\mathrm{Yu}^{18 \mathrm{~B}}$ was used. TBA value was expressed as $\mathrm{mg}$ of malonaldehyde $/ \mathrm{kg}$ of meat.

\section{Extraction and Analysis of Lipids}

Lipids of fish muscle were extracted with chiloroform-methanol $(2: 1, \mathrm{v} / \mathrm{v})$ according to the methoc of Bligh and Dyer. ${ }^{10)}$ Separation of the lipids into polar and nonpolar lipid fractions was carried out by the method of Tipton et al. ${ }^{203}$

For analysis of fatty acid composition, lipids were saponified with alcoholic $\mathrm{KOH}$, esterified with $\mathrm{BF}_{3}$-methanol and subjected to gas liquid chromatography. Conditions of gas liquid chromatography used are as follows: column, $0.3 \times 200$ $\mathrm{cm}$ glass tubing packed with Gas-chrom $\mathrm{P}$ coated with $20 \%$ DEGS; column and injection port temperatures, 195 and $250^{\circ} \mathrm{C}$, respectively; carrier gas, $\mathrm{N}_{2}$ at $30 \mathrm{~m} / / \mathrm{min}$.

\section{Water-Extraction of Muscle}

About $100 \mathrm{~g}$ of minced muscle of sample fish was extracted 3 times with 2 volumes of cooled distilled water. Each extraction period lasted for 30 min with occasional stirring. After each extraction, the extract was separated from the tissue residue by centrifugation. The extracted tissue residue was stored in a freezer at $-70^{\circ} \mathrm{C}$ until use.
Water-extracts were combined and subjected to dialysis.

\section{Dialysis of Water-Extract}

Water-extract was dialysed in a cellulose tubing against distilled water for $48 \mathrm{~h}$ in a refrigerator. The water was continuously stirred and changed once during dialysis. The diffusates were combined and concentrated in a rotary evaporator to an appropriate volume.

\section{Test for Catalytic Activity of Water-Extract}

Water-extract, dialysate and diffusate obtained above were freeze-dried separately. Then, each freeze-dried preparation was dissolved in a small amount of water and used for the following test: Each fraction of water-extract prepared was added back to the extracted muscle tissue in approximately the same proportion that it was originally in muscle and mixed thoroughly. The mixture was placed in a petri dish and cooked in an autoclave under the same conditions as mentioned above. After cooking, the sample was ground finely in a mortor and stored in a refrigerator at about $5^{\circ} \mathrm{C}$. During storage, TBA values of sample were determined to evaluate development of rancidity.

\section{Results and Discussion}

\section{Development of Rancidity in Different Species of Fish}

Contents and Fatty Acid Composition of Lipids of Samples: Lipid contents of muscles and fatty acid compositions of muscle lipids of 8 species of

Table 1. Moisture and lipid contents and fatty acid compositions of lipids in the muscles of fish samples

$(\%)$

\begin{tabular}{|c|c|c|c|c|c|c|}
\hline \multirow{2}{*}{ Fish } & \multirow{2}{*}{$\begin{array}{l}\text { Type of } \\
\text { muscle* }\end{array}$} & \multirow{2}{*}{$\begin{array}{l}\text { Moisture } \\
\text { content }\end{array}$} & \multirow{2}{*}{$\begin{array}{c}\text { Lipid } \\
\text { content }\end{array}$} & \multicolumn{3}{|c|}{ Fatty acid } \\
\hline & & & & Saturated & Monoenoic & Polyenoic \\
\hline Dusky sole & W & 81.7 & 0.71 & 29.4 & 21.2 & 49.4 \\
\hline Halibut & w & 79.7 & 0.76 & 27.6 & 15.6 & 57.0 \\
\hline Sablefish & $\mathrm{W}$ & 66.2 & 21.7 & 25.6 & 67.6 & 7.1 \\
\hline \multirow{2}{*}{ Flying fish } & $\{\mathrm{W}$ & 74.6 & 1.0 & 42.1 & 13.1 & 44.9 \\
\hline & $\hat{\imath}$ & 75.7 & 1.1 & 34.0 & 12.9 & 53.3 \\
\hline \multirow{2}{*}{ Horse mackerel } & $\{W$ & 76.0 & 2.4 & 35.3 & 30.6 & 34.1 \\
\hline & $\{\mathbf{R}$ & 73.0 & 6.1 & 35.5 & 28.7 & 35.7 \\
\hline \multirow{2}{*}{ Saury } & $\{w$ & 68.2 & 6.6 & 25.0 & 39.4 & 35.5 \\
\hline & $\{\mathrm{R}$ & 56.8 & 22.7 & 25.1 & 44.7 & 30.5 \\
\hline \multirow{2}{*}{ Sardine } & $\{W$ & 73.6 & 4.6 & 37.9 & 25.4 & 36.6 \\
\hline & IR & 66.2 & 13.3 & 35.3 & 24.6 & 40.1 \\
\hline \multirow{2}{*}{ Mackerel } & $\{W$ & 73.1 & 3.1 & 30.2 & 35.3 & 34.1 \\
\hline & $\{\mathbf{R}$ & 70.3 & 7.8 & 29.4 & 33.7 & 37.0 \\
\hline
\end{tabular}

\footnotetext{
* W, white muscle; $R$, red muscle.
} 
fish used in this experiment are shown in Table 1. Lipid contents of dusky sole and halibut were extremely low, compared with those of red meat species such as saury, sardine and mackerel. Dusky sole and halibut lipids were composed of polyenoic acid at relatively high percentage; $C_{20: 5}$ were $19.6 \%$ in dusky sole and $14.9 \%$ in halibut and $\mathrm{C}_{28: 6}$ were $14.3 \%$ in dusky sole and $22.8 \%$ in halibut. On the contrary, sablefish contained a large amount of lipid which was composed of higher percentage of $\mathrm{C}_{18: 1}(37.9 \%)$ and lower percentages of $\mathrm{C}_{20: 5}(1.3 \%)$ and $\mathrm{C}_{22: 8}(1.0 \%)$.

White muscle of flying fish contained lipids at extremely low concentration, which were composed of higher percentage of polyenoic acid $\left(\mathrm{C}_{22: 8}\right.$, $29.8 \%$, similarly in those of white meat fish mentioned above. In the lipid of white muscle of horse mackerel, percentage of polyenoic acid was somewhat low and that of monoenoic acid such as $\mathrm{C}_{18: 1}$ $(21.2 \%)$ was high. Fatty acid compositions of lipids of white and red muscles of these species were similar, though the lipid contents of red muscles were higher than those of white muscles. This is true of red meat species such as saury, sardine and mackerel as will be mentioned below.

In general, lipid contents in the meats of saury, sardine and mackerel varied considerably with seasons. The lipids of white muscles of saury, sardine and mackerel were similar in percentages of polyenoic acid. However, percentages of $\mathrm{C}_{20: 8}$ and $\mathrm{C}_{22: 8}$ were high in sardine $(12.2 \%)$ and in saury $(16.7 \%)$, respectively. Lipids in white muscle of mackerel were rich in monoenoic acid $\left(\mathrm{C}_{18: 1}, 28.7 \%\right)$.
Changes in TBA Values of White Meat Fish: Changes in TBA values of cooked and uncooked white muscles of dusky sole, halibut and sablefish during storage at about $5^{\circ} \mathrm{C}$ are shown in Fig. 1 . When white muscle of dusky sole was cooked at $100^{\circ} \mathrm{C}$ for $30 \mathrm{~min}, \mathrm{TBA}$ value increased to some extent. However, during storage the values of cooked sample decreased slowly, though uncooked sample showed increase in TBA values during storage for up to the first 2 days (Fig. 1-A). TBA values of both cooked and uncooked white muscles of halibut increased slightly in an early stage of storage. The increasing rate of values of the cooked sample was higher than that of uncooked one for up to the first 3 days of storage. In sablefish (Fig. 1-B), cooked white muscle showed TBA values less than $1 \mathrm{mg} / \mathrm{kg}$ throughout storage, though uncooked sample increased in the values to some extent.

In general, both cooked and uncooked white muscles of white meat species examined here did not show high TBA values throughout storage, showing that they were essentially not susceptible to oxidative rancidity.

Changes in TBA Values of Red Meat Fish: Changes in TBA values of white and red muscles of flying fish and horse mackerel during storage are shown in Fig. 2. TBA values of cooked white muscle of flying fish remained unchanged for up to the first 2 days of storage and then increased (Fig. 2-A). Similar pattern of change in TBA values was found in the uncooked sample, though the values were higher than those of the cooked sample. In red muscle of flying fish,

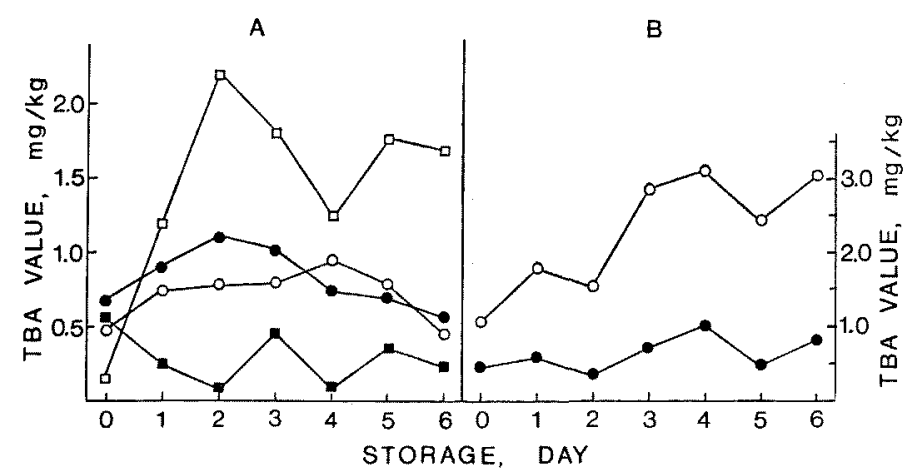

Fig. 1. Changes in TBA values of the white muscles of dusky sole, halibut and sablefish during storage at about $5^{\circ} \mathrm{C}$.

A: $-\square-$, dusky sole, uncooked; $-\square-$, dusky sole, cooked; $-\mathrm{O}-$, halibut, uncooked; -1-, halibut, cooked.

B, sablefish: - $\mathrm{O}-$, uncooked; - - cooked. Samples were cooked at $100^{\circ} \mathrm{C}$ for 30 $\min$. 
TBA values of both cooked and uncooked samples increased rapidly for up to the first 4 days of storage and then decreased slowly. The increasing rates of the values were considerably higher than those of the white muscle, regardless of cooking or not, indicating that in red muscle the lipids were highly susceptible to oxidation.

In horse mackerel (Fig. 2-B), both cooked and uncooked white muscles showed rapid increase in TBA values for up to the first 3 days of storage. TBA values of cooked and uncooked red muscle increased much more rapidly than those of white muscle during storage, though the patterns of increase in the value resembled each other. The cooked sample showed slightly lower increasing rate of TBA values than the uncooked one.

These results indicate that both cooked and uncooked white muscles of flying fish and horse mackerel are more susceptible to oxidative rancidity than those of white meat species of fish mentioned above.

Uncooked white muscle of saury increased in TBA values rapidly during storage, as shown in Fig. 3-A, though the values remained unchanged in the middle stage of storage. Similarly, TBA values of the cooked sample increased quickly in an early and advanced stages of storage. When red muscle of saury was cooked, TBA values

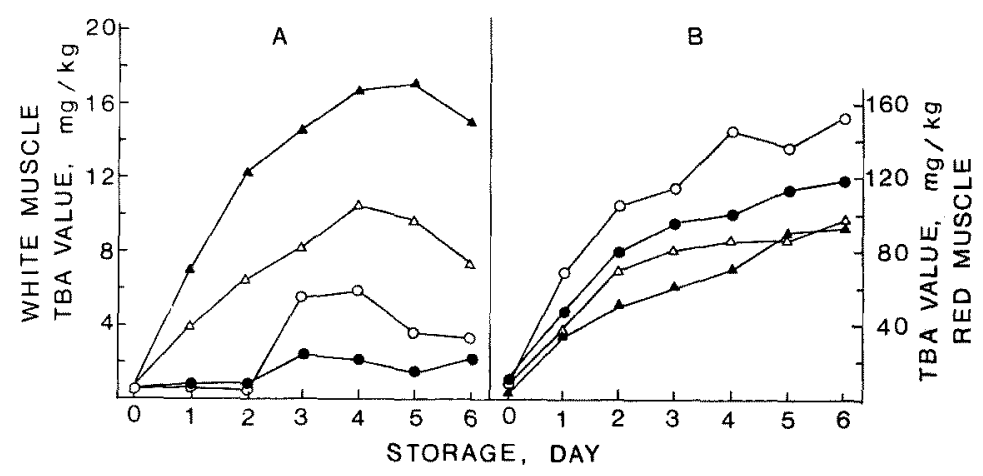

Fig. 2. Changes in TBA values of the white and red muscles of flying fish and jack mackerel during storage at about $5^{\circ} \mathrm{C}$.

A, flying fish: - - , white muscle, uncooked; - - , white muscle, cooked; $-\triangle-$, red muscle, uncooked; - - - , red muscle, cooked.

B, jack mackerel: Symboles are the same as those in Fig. 2-A. Samples were cooked at $100^{\circ} \mathrm{C}$ for $30 \mathrm{~min}$.

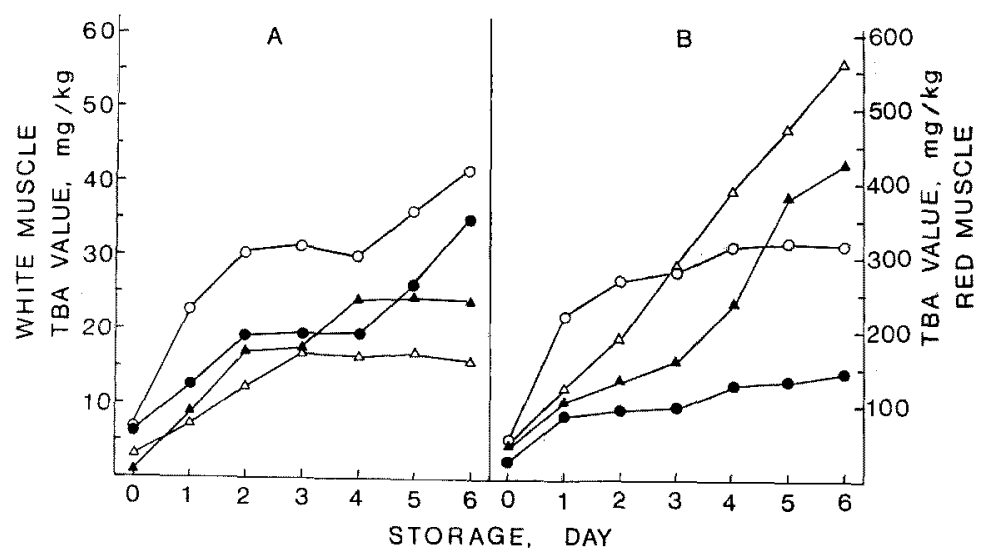

Fig. 3. Changes in TBA values of the white and red muscles of saury and sardine during storage at about $5^{\circ} \mathrm{C}$.

A, saury; B, sardine. Symboles are the same as those in Fig. 2-A. Samples were cooked at $100^{\circ} \mathrm{C}$ for $30 \mathrm{~min}$. 


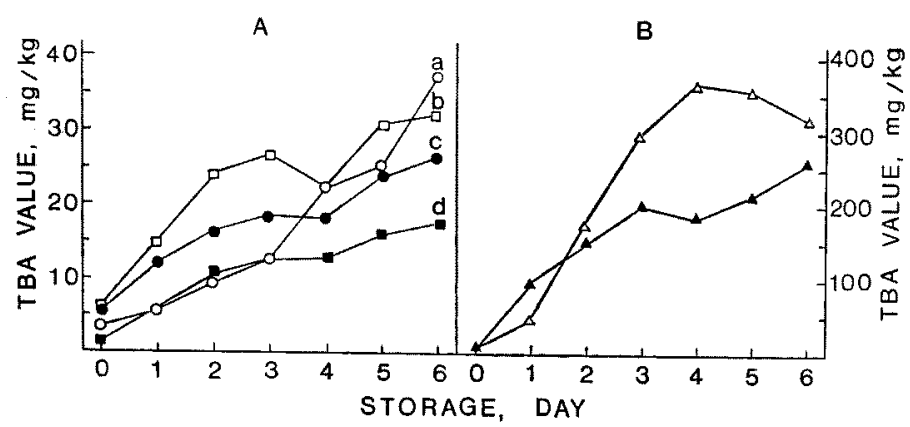

Fig. 4. Changes in TBA values of the white and red muscles of mackerel[during storage at about $5^{\circ} \mathrm{C}$.

A, white muscle: a, uncooked; b, cooked at $100^{\circ} \mathrm{C}$ for $15 \mathrm{~min}$; c, cooked at $100^{\circ} \mathrm{C}$ for $30 \mathrm{~min}$; d, cooked at $100^{\circ} \mathrm{C}$ for $60 \mathrm{~min}$. B, red muscle: $-\Delta-$, uncooked; $-\Delta-$, cooked at $100^{\circ} \mathrm{C}$ for $30 \mathrm{~min}$.

decreased. However, during storage for up to the first 3 days the values of both cooked and uncooked samples increased rapidly. The TBA values were higher in the cooked sample than in the uncooked one throughout storage. In sardine (Fig. 3-B), TBA values of the uncooked white muscle increased rapidly in an early stage of storage and then slowly, while those of cooked one increased slowly throughout storage. Red muscle of sardine showed rapid increase in TBA values during storage, regardless of cooking or not.

The results obtained with mackerel are shown in Fig. 4. TBA values of uncooked white muscle increased slowly for up to the first 3 days of storage and rapidly thereafter. When the sample was cooked for $15 \mathrm{~min}$ at $100^{\circ} \mathrm{C}$, the TBA value increased slightly. The values of cooked sample increased rapidly for up to the first 3 days of storage, and then slowly. In the sample cooked for $30 \mathrm{~min}$ at $100^{\circ} \mathrm{C}$, TBA values changed in a similar fashion to those of the sample cooked for $15 \mathrm{~min}$ at the same temperature, though its values were low. When the sample was cooked for 60 min and then stored, TBA values increased slowly throughout storage (Fig. 4-A). These results obtained indicate that at $100^{\circ} \mathrm{C}$, the longer the cooking time the lower the increasing rate of TBA values during storage at $5^{\circ} \mathrm{C}$. Similar results have been observed on warmed-over flavor of meats and explained in such a way that some compounds having antioxidant activity may be produced in a course of Maillard reaction to occur during cooking. ${ }^{20)}$ This might be true of fish meat. In red muscle (Fig. 4-B), TBA values of cooked sample were higher than those of uncooked one in an early stage of storage. However, during extended periods of storage the values of cooked sample became lower than those of uncooked one.

As mentioned above, TBA values of cooked white muscles of fish increased at different rates during storage at about $5^{\circ} \mathrm{C}$ according to fish species. The orders of increasing rates of TBA values were as follows; saury $>$ mackerel $>$ sardine $>$ horse mackerel $>$ flying fish $>$ sablefish $>$ halibut $>$ dusky sole. White meat species were essentially not susceptible to rancidity, despite the fact that their lipids were rich in polyunsaturated fatty acids, except in sablefish lipids. These results suggest that susceptibilities of cooked meats to oxidative rancidity during storage are closely related to their lipid and heme pigment contents rather than fatty acid compositions of lipids. The fact that TBA values increased at considerably higher rates in the red muscles of all examined fish seemed to support the above-mentioned deduction, because the red muscles contained both myoglobin and lipids at higher concentrations.

\section{Influence of Water-Extraction on TBA Value}

Influence of water-extraction on TBA value of mackerel white muscle were examined. Moisture and lipid contents of mackerel white muscle used were 68.0 and $9.8 \%$ (nonpolar lipid, $9.1 \%$; polar lipid, $0.72 \%$, respectively. Major constituent fatty acids of lipid were $\mathrm{C}_{18: 1}(26.6 \%), \mathrm{C}_{16: 0}$ $(20.5 \%)$ and $\mathrm{C}_{22: \theta}(13.4 \%)$ and total saturated, monoenoic and polyenoic acids were calculated as $32.3,32.4$ and $35.3 \%$, respectively. When the muscle was water-extracted 3 times, lipid content of the muscle decreased from 9.8 to $1.5 \%$ with increase in moisture content from 68.0 to $82.0 \%$. 


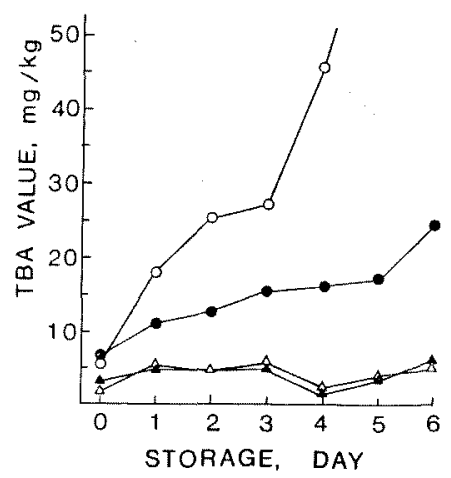

Fig. 5. Influence of water-extraction on TBA values of mackerel white muscle.

- - - uncooked; - - - cooked; $-\Delta-$,

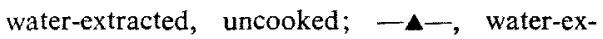
tracted, cooked. Samples were cooked at $100^{\circ} \mathrm{C}$ for $15 \mathrm{~min}$ and stored at about $5^{\circ} \mathrm{C}$.

The lipids of the extracted sample were composed of $0.82 \%$ of nonpolar lipid and $0.71 \%$ of polar lipid. Therefore, most of the lipids removed from the sample with water-extraction was nonpolar lipid, i.e. triglyceride; phospholipids mostly retained in the extracted sample. Major fatty acids in the lipids of extracted sample were $\mathrm{C}_{22: 8}$ $(23.3 \%), \mathrm{C}_{10: 0}(20.7 \%)$ and $\mathrm{C}_{18: 1}(20.3 \%)$. Percentages of saturated, monoenoic and polyenoic acids in the lipids were $32.5,24.1$ and $43.2 \%$, respectively.

Fig. 5 shows changes in TBA values of cooked and uncooked samples during storage at about $5^{\circ} \mathrm{C}$. TBA values of the cooked sample increased slowly during storage, though those of uncooked one increased rapidly. On the contrary, the extracted samples, regardless of cooking or not, showed extremely low TBA values throughout storage. From these results, it was presumed that some factors affecting lipid oxidation present in the muscle were almost removed with waterextraction, because the extracted sample did not almost undergo rancidity, despite the fact that it contained lipids at concentration enough to cause rancidity.

\section{Influences of Water-Extract on TBA Value}

Influences of dialysate and diffusate fractions of water-extract of mackerel white muscle on TBA values of cooked extracted muscle were examined. The results obtained are shown in Fig. 6. TBA values of cooked nonextracted sample (b) as well as uncooked nonextracted one (a) increased rapidly during storage. In cooked extracted sample (c), increase in TBA values was slow, indicating that water-extraction resulted in partial inhibition of lipid oxidation of the sample. When the water-extract was added back to the extracted muscle tissue and then cooked, TBA values of sample (d) increased during storage and the increasing rate was similar to that of the cooked nonextracted one (b). From these results, it appears that some factors affecting lipid oxidation present in the muscle were almost retained in the preparation of water-extract.

When the dialysate of water-extract was added back to the extracted muscle tissue and cooked, TBA values of the cooked sample (e) increased faster than that of the cooked extracted one (c) during storage. The extracted sample cooked

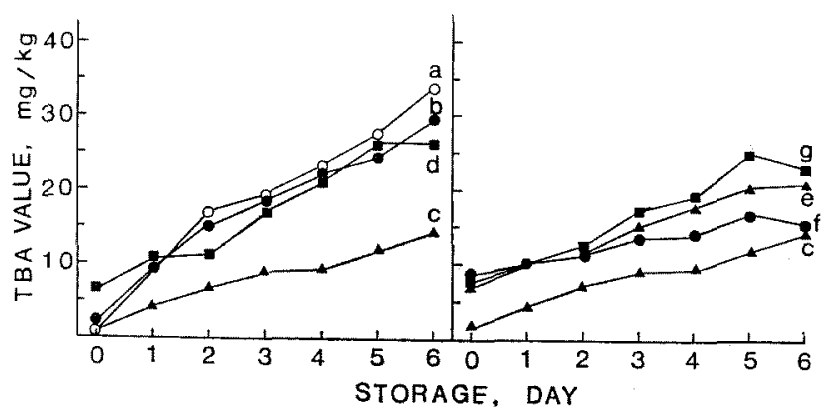

Fig. 6. Influences of the dialysate and diffusate fractions of water-extract on TBA values of waterextracted white muscle of mackerel.

a, nonextracted, uncooked; b, nonextracted, cooked; c, water-extracted, cooked; d, water-extracted, cooked with added water-extract; e, water-extracted, cooked with added dialysate fraction; f, water-extracted, cooked with added diffusate fraction; $g$, water-extracted, cooked with added both dialysate and diffusate fractions. Samples were cooked at $100^{\circ} \mathrm{C}$ for $15 \mathrm{~min}$ and stored at about $5^{\circ} \mathrm{C}$. 
with the diffusate (f) showed slightly lower in the rate of increase in TBA values than the extracted sample cooked with the dialysate (e). This seemed to show that the diffusate had no influence on lipid oxidation of cooked meat. However, when the diffusate was combined with dialysate, added back to the extracted muscle tissue and cooked, the rate of increase in TBA value of the sample (g) during storage was slightly higher than that of the cooked extracted sample treated with the dialysate alone (e). Slightly higher initial TBA values of samples shown as curves $d, e, f$ and $g$ in the figure seemed to be due in part to frozen storage at $-70^{\circ} \mathrm{C}$ for 10 days before use.

From these results, it is clear that major factors involved in the lipid oxidation of cooked mackerel white muscle are fractionated to the dialysate fraction by dialysis, and that some substances in diffusate fraction is concerned in the lipid oxidation to some extent in the presence of dialysate. These results are different markedly from those of Sato and Hegarty ${ }^{11)}$ who investigated warmedover flavor in cooked beef; the diffusate showed much higher activity to cause an increase in TBA value of the water-extracted beef than the dialysate. After various experiments, they concluded that mechanism of the reaction responsible for warmedover flavor in cooked beef might be attributed to lipid oxidation catalyzed by nonheme iron.

At present, however, in the case of fish meat heme pigments as well as nonheme iron should be suspected to be substances responsible for causing oxidative rancidity of cooked meat, differing from warmed-over flavor of cooked beef. Further study is necessary to elucidate the mechanism of reaction leading to development of rancid off odor or flavor of cooked fish meat during storage in a refrigerator.

The authors wish to thank Mr. T. Tanaka and Mr. T. Yoshioka for their assistances in the experimental work. This work was partly supported by Grant-in-Aid for Scientific Research from the Ministry of Education, Science and Agriculture.

\section{References}

1) C. Koizumi, Cao thi Kieu-Thu, and J. Nonaka: Nippon Suisan Gakkaishi, 45, 1307-1312 (1979).

2) M. W. Zipser and B. M. Watts: Food Technol., 15, 318-321 (1961).

3) M. T. Younathan, J. K. Oon, and Rokiah, B. Mohd, Yusof: J. Food Sci., 48, 176-178 (1983).

4) M. Jacobson and H. H. Koehler: J. Agr. Food Chem., 18, 1069-1072 (1970).

5) A. M. Pearson, J. D. Love, and F. B. Shorland: Adv. Food Res., 23, 2-74 (1977).

6) E. L. Ruenger, C. A. Reineccius, and D.R. Thompson: J. Food Sci., 43, 1198-1200 (1978).

7) M. T. Younathan and B. M. Watts: Food Res., 25, 538-543 (1960).

8) K. Yamauchi: Bull. Fac. Agric. Univ. Miyazaki, 19, 147-154 (1972).

9) B. R. Wilson, A. M. Pearson, and F. B. Shorland: J. Agr. Food Chem., 24, 7-11 (1976).

10) J. O. Igene and A. M. Pearson: J. Food Sci., 44, $1285-1290$ (1979).

11) K. Sato and G. R. Hegarty: J. Food Sci., 36, 1098-1102 (1971).

12) K, Yamauchi: Bull. Fac. Agric. Univ. Miyazaki, 19, 397-404 (1972).

13) J. D. Love and A. M. Pearson: J. Agr. Food Chem., 22, 1032-1034 (1974).

14) J. D. Love and A. M. Pearson: J. Agr. Food Chem., 24, 494-498 (1976).

15) J. O. Igene, J. A. King, A. M. Pearson, and J. I. Gray: J. Agr. Food Chem., 27, 838-842 (1979).

16) B. MacDonald, J. I. Gray, and L. N. Gibbins: J. Food Sci., 45, 893-897 (1980).

17) B. R. Schricker and D. D. Miller: J. Food Sci., 48, 1340-1343 (1983).

18) R. O. Sinnhuber and T. C. Yu: Yukagaku, 26, 259-267 (1977).

19) E. C. Bligh and W. J. Dyer: Can. J. Biochem. Physiol., 37, 911-917 (1959).

20) C. L. Tipton, J.W. Paulis, and M. D. Pierson: J. Chromatogr., 14, 486-489 (1964).

21) K. Sato, G. R. Hegarty, and H. K. Herrig: $J$. Food Sci., 38, 398-403 (1973). 